\title{
FORMACIÓN Y CULTURA ESCRITA: LOS LIBROS DEL AGRIMENSOR FRANCISCO FALCÓN (1764)
}

\author{
Training and written culture: the books of the land surveyor \\ Francisco Falcón (1764)
}

\section{Amparo García Cuadrado ${ }^{\alpha}$}

Fecha de recepción: 27/11/2019 • Fecha de aceptación: 02/01/2020

Resumen. El artículo aborda el estudio de la biblioteca privada del agrimensor murciano de la primera mitad del Setecientos Francisco Falcón de los Reyes, un claro ejemplo de la relación existente entre educación y cultura escrita. A partir de los datos extraídos de un inventario post mortem y de la posterior tasación y partición de bienes entre los herederos, se lleva a cabo el análisis cuantitativo y cualitativo de dicha biblioteca. Previamente se dibuja el perfil vital de este geómetra y de su familia descendiente de esclavos (cristianos nuevos), y la precariedad formativa de estos profesionales en su tiempo. El análisis cuantitativo del fondo bibliográfico y su cotejo con otras colecciones privadas pertenecientes a ámbitos socioeconómicos semejantes señalan la importancia numérica de dicha colección. El estudio cualitativo de autores y títulos muestra, por un lado, el alto grado de formación matemática del dueño como receptor de la corriente científica pre-ilustrada, fundamentalmente los novatores valencianos y, por otro, la finalidad con que aquellos libros fueron incorporados al fondo de la colección. Junto a la biblioteca que podríamos denominar profesional, de marcado carácter científico, los impresos de materia religiosa inventariados conforman otro interesante porcentaje de naturaleza catequética en sus diversos niveles formativos.

Palabras clave: biblioteca privada; Murcia; siglo XVIII; agrimensura; Francisco Falcón.

\footnotetext{
a Dpto. de Información y Documentación. Facultad de Comunicación y Documentación. Universidad de Murcia. Campus de Espinardo.30100 Murcia. España. ampagar@um.es
} 
Abstract. This article approaches the study of the private library of the Murcian land surveyor Francisco Falcón de los Reyes, from the first half of the eighteenth century, which constitutes a clear example of the relationship between education and written culture. From the data extracted from a postmortem inventory and the subsequent appraisal and partition of goods among the heirs, we carried out a quantitative and qualitative analysis of said library. First, the text provides a biographical profile of this geometer, a descendant of slaves (new Christians), and describes the formative precariousness of these professionals in their time. The quantitative analysis of the bibliographic collection and its comparison with other private collections from similar socioeconomic fields indicate the importance of this particular collection. The qualitative study of authors and titles shows, on one hand, the high degree of mathematical training of the subject, who is shown to be a recipient of the fundamentally Valencian pre-illustrated reformist scientific mainstream, and, on the other hand, the purpose with which those books were incorporated into the funds of the collection. Together with the library, which we could call professional, due to its scientific nature, the inventoried religious matter in the form of printed documents makes up another interesting part of the collection, one of a catechetical nature in its various formative levels.

Keywords: private library; Murcia; $18^{\text {th }}$ Century; land surveying; Francisco Falcón.

\section{INTRODUCCIÓN}

La íntima relación existente entre formación y cultura escrita que señala la documentación notarial hace de ella una fuente de información fundamental para abordar el grado de alfabetización, lectura y escritura de los individuos de ambos sexos y entre los diversos estamentos sociales dentro de unas coordenadas espacio temporales determinadas. Del mismo modo que las investigaciones sobre alfabetización en España han recurrido al análisis de las firmas contenidas en fuentes de diversa naturaleza (judiciales, fiscales, notariales, etc.), los trabajos encaminados a conocer la distribución del libro entre los distintos grupos sociales han encontrado en las fuentes notariales, más en concreto en el inventario post mortem, el instrumento más eficaz de obtención de datos, a pesar de las limitaciones que dicha fuente presenta. ${ }^{1}$ Por ello, quienes

\footnotetext{
1 Antonio Viñao Frago, «La historia de la alfabetización a través de las fuentes notariales. Aportaciones provisionales sobre el proceso de alfabetización en Murcia (1760-1860)», en Aproximación a la
} 
estamos familiarizados con esta documentación y con la ya abundante bibliografía sobre bibliotecas privadas españolas del siglo XVIII hemos podido constatar que la posesión de patrimonios bibliográficos de cierta relevancia queda circunscrita a una elite social ciertamente instruida: alto clero, nobleza y profesiones liberales más prestigiosas, junto con aquellos que habían conseguido disfrutar de cargos administrativos relevantes como abogados de los Reales Consejos, altos empleos de la Inquisición y representantes del poder real en los distintos reinos. ${ }^{2}$ Por el contrario, el valor cuantitativo de la biblioteca privada disminuye de manera significativa cuando nos acercamos a aquellos otros integrantes de la sociedad civil que ganaban su sustento en el desempeño de actividades de menor rango, pero que requerían de una formación específica para su cabal ejercicio. Naturalmente, tanto en unos como en otros, la presencia de libros entre los bienes inventariados puede estar indicando una más que probable actividad lectora y, en consecuencia, aquellos ejemplares serían reflejo de sus gustos lectores, pero también de la preparación intelectual y/o profesional alcanzada por el dueño y, en definitiva, de los motivos o necesidades lectoras que pudieron dar lugar a la adquisición de los ejemplares que conforman la biblioteca.

Dentro del segundo grupo citado se integran los profesionales de la agrimensura, un oficio de gran utilidad en el desarrollo social, pero que no siempre había gozado de la suficiente estimación por creer que con ligeros conocimientos podía desempeñarlo cualquiera, de ahí que una parte, según un experto del siglo XIX, obtenía «el título sin tener ningún conocimiento, y que la otra parte se hallaba desempeñada por hombres rústicos, ignorantes é incapaces de aprender, no sabiendo apenas ni aun escribir sus nombres». ${ }^{3}$ La situación descrita, a pesar de que pueda parecer exagerada, no debía de ser muy diferente a la vivida por el sector en la Murcia de la primera mitad de la Centuria Ilustrada, aunque había sus excepciones. En 1722, el acta del concejo murciano de 16 de junio

investigación histórica a través de la documentación notarial, comp. Antonio Eiras Roel et al. (Murcia: Universidad, 1985), 38-42 y 50-55.

2 Una buena síntesis sobre los estudios en esta materia la podemos encontrar en Inmaculada Arias de Saavedra, "Libros, lectores y bibliotecas privadas en la España del siglo XVIII", Chronica nova 35 (2009): 15-61. Más reciente es la realizada por Francisco José Ramiro, «Alfabetización, lecturas y bibliotecas en la Granada del siglo XVIII» (Tesis doctoral, Universidad de Granada, 2017), 273-279. https://dialnet.unirioja.es/servlet/tesis?codigo=147594

${ }^{3}$ Isidro Giol y Soldevilla, Tratado de Agrimensura. $3^{\circ}$ ed. corr. y aum. (Madrid, 1889), 306. 
daba cuenta de la precariedad observada en dicho arte por dos conocidos agrimensores, quienes solicitaban ser nombrados veedores para tratar de frenar la situación de decadencia existente. El memorial remitido a las autoridades municipales señala que:

[...] existen seis agrimensores nombrados y otros que ejercen sin poderlo hacer por falta de ciencia y no concurrir en algunos las circunstancias que deven tener para dicho arte, de que resulta grave perjuicio a la República, lo que no remedian los que están examinados, porque los unos por los otros lo omiten $[\ldots]^{4}$

Ante tan alarmantes noticias, la Ciudad acordaba que Pedro Navarro Michael y su colega Rafael Campaña fueran nombrados veedores del gremio. A partir de entonces, ambos expertos serían los encargados de examinar a todos aquellos que solicitasen la obtención del título correspondiente para el ejercicio profesional. Es de imaginar que la medida pudo ayudar a mejorar la formación de los interesados al exigírseles los conocimientos pertinentes en aritmética y geometría, materias esenciales del diseño curricular. El solicitante era examinado sobre las reglas geométricas elementales y prácticas, aritmética especulativa y demostrable, medición de superficies planas y el recortado de las que se le ordenaban, más otras diligencias propias del oficio. Solo así, una vez demostrada su aplicación, podía ser tenido por hábil y capaz para obtener la titulación..$^{5}$ A pesar de estos intentos por mejorar la profesionalidad del agrimensor, la precariedad del oficio obedecía a la falta de centros de formación específicos y a la existencia exclusiva de un aprendizaje de padres a hijos. En el vecino reino de Valencia la actividad agrimensora durante la primera mitad del XVIII no era distinta a la que hemos descrito. Como bien ha puesto de relieve Faus Prieto, la agrimensura se encontraba en manos de una suerte de «expertos en agricultura», peritos carentes de titulación y procedentes de familias de larga tradición agrimensora que compartían su trabajo con los novatores, aunque existía un fuerte contraste en la formación matemática de unos y otros. Precisamente, la influencia ejercida por estos pre-ilustrados será determinante en la aparición, unas décadas más tarde, de la figura del agrimensor

\footnotetext{
${ }^{4}$ Archivo Municipal. Murcia (A.M.M.). Acta Capitular, 16-VI-1722, f. 70r.

${ }^{5}$ A.M.M. Acta cap. de 1763, f. 166r.
} 
profesional con una titulación específica avalada por la Academia de Bellas Artes de San Carlos. ${ }^{6}$

Pues bien, en aquel contexto de marcada endotecnia y carencia de cauces apropiados de formación académica iniciaba su trayectoria Francisco Falcón de los Reyes, de quien sabemos llegó a ser un experto matemático agrimensor público al servicio de las necesidades del propio concejo murciano. Pero ¿de qué manera pudo haberse formado en la medición y nivelación de tierras, conducción de aguas, elaboración de planos y otras tareas propias del agrimensor? Nada sabemos al respecto, aunque por fortuna contamos con el inventario de una biblioteca cuyo fondo debió de ser determinante en el logro de una notable formación científica, más allá de la mera preparación empírica, nota común entre aquellos profesionales.

\section{EL RETRATO DE UN LECTOR Y SU FAMILIA}

Antes de llevar a cabo el análisis del conjunto bibliográfico referido, parece conveniente tratar de dibujar, con los escasos datos localizados, un perfil vital del geómetra. Francisco había nacido en Murcia a inicios del siglo XVIII en el seno de la familia Falcón de los Reyes, cuyos orígenes berberiscos fueron denunciados ante la autoridad municipal cuando el joven Francisco solicitaba la obtención del título de agrimensor en agosto de 1722. Según su propia declaración, se había examinado ya en Granada y obtenido real provisión auxiliar para que no se le impidiese usar de sus conocimientos en su ciudad natal. ${ }^{7}$ La respuesta a su petición no se haría esperar; un mes más tarde, los representantes más destacados de la profesión le negaban tal posibilidad. Pero veamos el dictamen de los peritos que deja traslucir la nula parcialidad de quienes debían velar por el oficio que representaban. Dice así el acta:

Vióse memorial de Pedro Navarro Michael, Rafael Campaña y Cristóval Martínez Fortún, en su nombre y en los demás del arte

\footnotetext{
${ }^{6}$ Alfredo Faus Prieto, Mapistes. Cartografía i agrimensura a la València del segle XVIII (Valencia: Edicions Alfons el Magnànim; Generalitat Valenciana, 1995), 51. Del mismo autor: «El ejercicio profesional de la agrimensura en la España del siglo XVIII: titulación académica y formación teórica de los peritos agrimensores», Llull 18 (1995): 425-440.
}

${ }_{7}$ A.M.M. Acta cap. 8-VIII-1722, f. 102r. 
Agrimensor de esta jurisdicción [...] pidieron a la Ciudad tuviera a bien no admitir a examen persona alguna en que no concurriesen las calidades estimables a la decencia del Arte, por haver sido siempre practicado por christianos viejos y personas de todo crédito como es notorio, cuya diligencia ejecutaron con noticia de que Francisco, que se apellida Falcón, solicitó examinarse de dicho Arte, y que teniéndola aora de que a acudido a Granada, dónde no le conocen por ser natural de esta ciudad y haviéndose criado en ella, y logrado dicho examen y querer usar del Arte en esta jurisdicción, siendo opuesto a lo prevenido por ordenanzas no se admitan exámenes de otros pueblos y que siendo como es dicho Francisco disímil de los suplicantes por ser hijo de jeneración de berberiscos y esclavos herados, como es franco y notorio, y que dicha expresión la hacen sin ánimo de injuriarlo, sí por convenir a su intento, y así lo juraron con las demás expresiones de dicho memorial, suplicando se les de licencia para en caso de conseguir su intento el pretendiente, de que esta parte cesen en su empleo y entreguen sus títulos en la Escribanía Mayor de este Ayuntamiento. ${ }^{8}$

Es evidente que los rasgos propios de su raza y el rostro herrado de sus ancestros esclavos seguían influyendo en la falta de consideración moral del solicitante y en su exclusión social, al punto de amenazar a los munícipes con la renuncia a sus cargos si se le admitía como un igual. No debemos olvidar que el color de la piel de un individuo y sus rasgos físicos eran signo de brutalidad y de inferioridad, como lo eran las señales o marcas de fuego, aunque el antiguo esclavo y sus descendientes gozasen ya de carta de libertad, sus nombres estuviesen cristianizados y hubieran adoptado incluso el apellido de quien los libertó. ${ }^{9}$ El caso es que la decisión de los munícipes quedó en suspenso mientras se realizaban las consultas pertinentes a los abogados del ayuntamiento, siguiendo así el procedimiento habitual.

\footnotetext{
${ }^{8}$ A.M.M. Acta cap. 26-IX-1722, f. 122v.

${ }_{9} \mathrm{M}^{\mathrm{a}}$ Dolores Marín Cruz, «La Libertad y su Criada, la Esclavitud», Cuadernos de Historia del Derecho, vol. extraordinario (2010): 291-293. Desconocemos el caso concreto de esta familia de esclavos, pero tenemos documentada la compra de un oficio de jurado por parte de un tal don Francisco Falcón, apellido emparentado con otros miembros de la clase rectora urbana en 1720. Archivo Histórico Provincial. Murcia (A.H.P.). Protocolo 2965, ante Bolmás Peinado, f. 1r. (4ª f.).
} 
Según la normativa imperante, los sujetos que habían conseguido mostrar su capacidad en la capital granadina eran examinados nuevamente, un requerimiento que a Francisco se le había negado. Por ello, el solicitante dirigía sus pasos a la Real Chancillería de Granada y en enero de 1723 volvía a pedir se le concediese «licencia para usar en ella [Murcia] y su jurisdicción el Arte de Agrimensor en fuerza de la Real Provisión de S.M. y Señores de la Real Chancillería de Granada que para ello a obtenido». ${ }^{10}$ Por su parte, la reacción de las autoridades fue dirimir el problema en la Corte, mediante una representación al monarca. A partir de aquí, el silencio de las actas impide saber la resolución tomada en Madrid, pero años más tarde, Francisco Falcón se encontraba poniendo sus amplios conocimientos al servicio del ayuntamiento como agrimensor público. Tenemos documentados los trabajos de empedrado y nivelación en algunas plazas y calles, ${ }^{11}$ y su participación como comisionado experto en la planificación de un molino en la acequia mayor de la Aljufía. ${ }^{12}$ De su mano conocemos también un Plan Geometryco de 1732, conservado en el Arxiu del Regne de València, sobre el término de Beniel, el Barranco del Moro y parte de la huerta de Orihuela, un dato de interés que demuestra la actuación del geómetra en el reino limítrofe y sus posibles contactos con otros profesionales valencianos ${ }^{13}$ (figura 1).

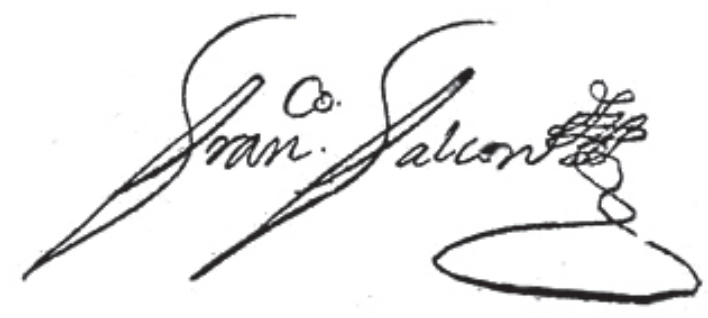

Figura 1. Firma y rúbrica de Francisco Falcón en 1742.

Resulta evidente que el lastre de su origen no le impidió hacerse un hueco entre los agrimensores más prestigiados; incluso su propia madre, Baltasara de los Reyes Alonso, pudo disfrutar de la venta de la sal,

\footnotetext{
10 A.M.M. Acta cap., 19-I-1723, f. 13r.

11 A.M.M. Acta cap., 11-XI-1738, f. 300r.

12 Acta cap., 22-X-1736, f. 300r.

${ }_{13}$ Faus Prieto, Mapistes, 348-349 y figura XVI en color.
} 
un producto estanco que, como el aceite o el tabaco, estaba sometida al control de la Corona. Lo cierto es que gracias a sus industriosos miembros y a las posibles relaciones con la elite rectora la economía de la familia no debía de ser menguada. Los testamentos de Baltasara ${ }^{14}$ y de una de sus hijas, Isabel, son buena muestra de la situación acomodada alcanzada por el clan, cuyos progenitores parece que supieron fomentar la educación de sus vástagos aunque la madre no supiera escribir. ${ }^{15}$ En una época poco propicia para la formación de las féminas murcianas, tanto Rosa como su hermana Isabel sabían firmar, con un dominio del cálamo más que notable, habilidad que no todas las «cristianas viejas» podían exhibir en aquella Murcia del Setecientos (figura 2).
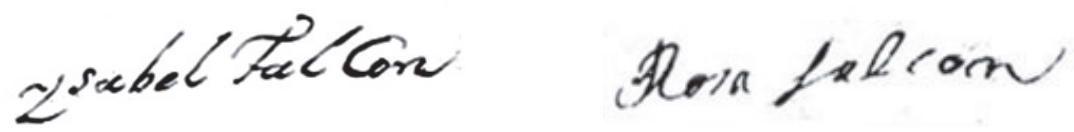

Figura 2. Firmas de las hermanas Falcón de los Reyes.

Ahora bien, la laboriosidad de Francisco Falcón no se limitaba a la medición y nivelación de tierras, elaboración de mapas o deslindes de propiedades, pues sus actividades se extendían a gestionar el arriendo de las tierras familiares y al negocio de libros. En concreto, sabemos de las relaciones comerciales mantenidas con el mercader de libros Antonio Roncales Sanz, aragonés establecido en los años 30 en el barrio de San Pedro, en la calle del Pilar, junto al impresor Felipe Teruel, quien con el tiempo lograba fundar la más importante oficina tipográfica. En efecto, en abril de 1742 Falcón y Roncales declaraban ante notario haber comprado a plazos la cuantiosa biblioteca del médico Alfonso Mesía por 5.000 reales en cabeza del segundo, si bien el agrimensor había sido su fiador. Las condiciones del convenio alcanzado entre ambos obligaban al librero a ir vendiendo la citada colección y las ganancias obtenidas debían ser entregadas a Falcón para el pago anual de 1.000 reales. A Roncales correspondía empergaminar y componer a su costa los ejemplares que precisasen reparación, y el gasto de pergaminos para la

\footnotetext{
${ }_{14}$ A.H.P. Murcia. Prot. 2644, ante Cano de Santayana, f. 313r.-315 v. «Testamento de Melchora de los Reyes Alonso».

15 A.H.P. Murcia. Prot. 2943, ante Jilarte Valdivieso, f. 312-314v. «Inventario de los vienes que han quedado por la fin y muerte de Isabel falcón, viuda de Nicolás Román».
} 
encuadernación correría a mitad entre los asociados. ${ }^{16}$ Probablemente esta relación comercial pudo haber influido en el matrimonio contraído en segundas nupcias por el librero con Rosa Falcón, una de las hermanas de Francisco, en marzo de 1746, boda celebrada en San Pedro, parroquia común de los contrayentes; como testigos del evento figuran dos nombres destacados de la elite ciudadana, el regidor Rafael Lisón y el notario Cano Santayana, signo evidente del contexto social en que para entonces se desenvolvían. ${ }^{17}$ La relación con su cuñado le llevaría también a participar en la venta de impresos, al menos es lo que se desprende del testamento del aragonés (1750) al declarar que le había entregado a su cuñado Francisco «dos juegos de libros de Scotti que vendió a don Gregorio Conde, y otras cantidades» que no especifica. ${ }^{18}$ Es presumible suponer, por tanto, que ese contacto directo con el mundo del libro a través de su cuñado pudo facilitarle la adquisición de títulos de su interés con relativa facilidad.

Tras su fallecimiento en marzo de 1764, la colección, igual que el resto de sus bienes, pasó a sus hermanas como únicas herederas al haber muerto su esposa, Bárbara Olarte, matrimonio que no tuvo descendencia. ${ }^{19}$ En realidad, todos los bienes de la familia Falcón de los Reyes continuaban indivisos desde la desaparición de los progenitores y lo seguirían estando una vez muerto Francisco, pues ambas hermanas, viudas, vivían en la casa familiar de la calle del Pilar. Solo la muerte de Isabel hizo preciso el inventariado de aquellos bienes comunes para su división entre los tres herederos: Rosa, su sobrino Antonio Román Falcón, también geómetra, y una adolescente, nieta de Isabel, cuyos padres ya habían fallecido. Es precisamente esta documentación, junto al expediente de tasación y partición subsiguiente, la que nos va a permitirevaluar el contenido de aquella biblioteca, en

\footnotetext{
16 A.H.P. Murcia. Prot. 2636, ante Cano de Santayana, f. 117r. y v. «Francisco Falcón y Antonio Roncales, escriptura de combenio».

17 Amparo García Cuadrado, «Noticias sobre el impresor Felipe Teruel Martínez», Anales de Documentación 18, n. ${ }^{\circ} 1$ (2015): 2-3. https://digitum.um.es/digitum/bitstream/10201/44071/1/document $\% 20 \% 2848 \% 29$.pdf

18 A.H.P. Murcia. Prot. 2644, ante Cano de Santayana, f. 317r.-319v.

19 A.H.P. Murcia. Prot. Prot. 2944, ante Jilarte Valdivieso, Expediente de los Falcón: «Poder para testar dado por Francisco Falcón al presbítero y ecónomo de la parroquia de San Pedro don Ambrosio Costa», f. 40r. y Testamento de FranciscoFalcón, f. 43r.- 47r.
} 
gran parte profesional, pero que también pudieron disfrutar otros miembros de la familia. ${ }^{20}$

\section{LA COLECCIÓN BIBLIOGRÁFICA: TASACIÓN Y MATERIAS}

En el momento de su inventariado la colección descansaba en un «estante mediano de pino con ocho divisiones y rejilla de arambre», un tipo de mueble muy común entre los murcianos con bibliotecas más o menos surtidas, no solo como elemento de exhibición sino como medida de conservación de los ejemplares. ${ }^{21}$ Este hecho permite apreciar el interés del propietario por aquellos bienes e, incluso, un deseo de facilitar el acceso a los ejemplares frente a quienes, por falta de utilización, preferían conservarlos en arcones o recipientes similares. Aquel mueble «mediano» daba cabida a 36 títulos con un total de 62 volúmenes, número ciertamente modesto, pero en sintonía con algunas colecciones del clero, boticarios, cirujanos e incluso a las de ciertos regidores y escribanos que no alcanzan la treintena, como tampoco lo hacían las de otros profesionales de menor rango en la ciudad de Murcia. Entre ellos podemos citar la biblioteca de un capitán de caballos con 30 títulos inventariado en $1711,{ }^{22}$ los mismos ejemplares que la formada por el sacristán de San Bartolomé en 1717;23 en 1722 la de un comerciante de tejidos no se acercaba a la veintena, ${ }^{24}$ y Juan Antonio Pelegrín, un maestro de obras hidráulicas y torcedor de seda que había trabajado en el diseño de Puente Viejo de Murcia y en el pantano de Lorca, al final de su vida (1721) contaba con una colección de 26 ejemplares y un buen lote de manuscritos de carácter técnico. ${ }^{25}$ En años posteriores, el conocido maestro de obras,

\footnotetext{
20 A.H.P. Murcia. Prot. 2943, ante Jilarte Valdivieso, f. 312r.-314v. «Inventario de los vienes que han quedado por la fin y muerte de Isabel falcón, viuda de Nicolás Román» (1767). Prot. 2944, ante Jilarte Valdivieso "Autos de partición de los vienes que han quedado por el fallecimiento de Antonio Falcón y Baltasara de los Reyes, y los de Isabel Falcón hija de estos y demás herederos» (1768), foliación propia.

${ }^{21}$ A.H.P. Murcia. Prot. 2943, f. 312v.

22 A.H.P. Murcia. Prot. 3670, ante Miguel de las Peñas Torralba, f. 125 v-126 r.

${ }^{23}$ A.H.P. Murcia. Prot. 3677, ante Miguel de las Peñas Torralba, f. 396r.-297r.

24 A.H.P. Murcia. Prot. 3297, ante López Mesas, f. 108v.

25 A.H.P. Murcia. Prot. 2565, ante Bolmás Peinado, f. 130r.-132r. Su biblioteca no está publicada, pero hay noticias sobre su actividad en: Concepción de la Peña Velasco, El Puente Viejo de Murcia (Murcia: Universidad de Murcia, 2001).
} 
Martín Solera, contemporáneo de Falcón, contaba con una estupenda biblioteca profesional compuesta por 20 títulos, ${ }^{26}$ mientras que un acaudalado escribano del número, Alejandro López Mesas, apenas alcanzaba la veintena en 1766. ${ }^{27}$ En los años finales de la centuria (1790), el agrimensor Manuel Sánchez Villar dejaba a su sobrino, también agrimensor, un lote de 24 libros que comprendía «sus tratados, Arismética, Geometría, Matemática y el Hijo de David perseguido» valorados en 100 reales. ${ }^{28}$ Así pues, la biblioteca que estudiamos podía encuadrarse entre las más surtidas de su entorno social que, por otra parte, eran escasas en Murcia.

Dada la ausencia de bibliotecas de geómetras estudiadas, sirva como cotejo las constituidas por algunos maestros de obras que como los agrimensores hacían de las matemáticas una ciencia aplicada y cuyo nivel socioeconómico era muy similar. Expongamos tres casos fuera del área murciana, todas ellas bibliotecas inventariadas en los años 40 de la centuria, que pueden servirnos para establecer un cierto paralelismo cuantitativo con la que estudiamos. Así, la colección bibliográfica del maestro de obras compostelano José de Seixas, muerto en 1740, disponía de 15 títulos en 25 cuerpos; ${ }^{29}$ el maestro Juan de Larrea, un vizcaíno de Durango, contaba en 1741 con una treintena de libros; ${ }^{30}$ y el inventario de bienes del burgalés Pedro Juan Laviesca, un reconocido maestro muerto en Sevilla en 1749, recoge tan solo 28 libros a pesar de disfrutar su dueño de una desahogada situación económica. ${ }^{31}$ Con estos datos en la mano, podemos afirmar que la colección del murciano era ciertamente cuantiosa dentro de su estatus social y profesional.

\footnotetext{
${ }^{26}$ Concepción de la Peña Velasco, «La biblioteca de Martín Solera, un maestro de obras del siglo XVIII en Murcia», Imafronte 1 (1985): 73-86.

27 A.H.M. Murcia. Prot. 2838, ante Fernández Rubio, f. 452r.-453v.

${ }_{28}$ A.H.P. Murcia. DIP. 6372/15, f. 37v.

${ }^{29}$ Miguel Taín Guzmán, «El taller y la biblioteca del maestro de obras compostelano José de Seixas», Cuadernos de Estudios Gallegos 106 (1993/94): 263-275.

${ }^{30}$ José Azanza López, «La biblioteca de Juan de Larrea, maestro de obras del siglo XVIII», Príncipe de Viana 211 (1997): 295-328.

31 Yolanda Gil Saura, «Pedro Juan Laviesca de la Torre, un arquitecto itinerante en la España del siglo XVIII», Anuario del Departamento de Histona y Teoria del Arte 11 (1999): 169-183.
} 
En cuanto al valor crematístico de la colección, sabemos que en mayo de 1768 el librero francés Francisco Fache, establecido en la calle de la Platería, aceptaba el nombramiento de tasador tras efectuar la obligada diligencia de jurar cumplir bien y fielmente con la obligación del encargo encomendado. ${ }^{32}$ Es de suponer que, dada la gran experiencia del perito en la valoración y compra de bibliotecas de segunda mano, la tasación de los ejemplares debió de hacerse ajustada. ${ }^{33}$ El monto total fue calculado en cerca de 500 reales de vellón, dineros donde se incluían el armario de pino que contenía los ejemplares. ${ }^{34}$ El número de volúmenes por título, su formato, la calidad de la encuadernación y el estado de conservación ayudarían a determinar, probablemente, el precio señalado. Aunque no siempre se especifica el tipo de recubrimiento de los ejemplares, 4 de ellos lo estaban en "pasta francesa», calidad nada habitual entre los libros de los murcianos. En general, el recubrimiento en pasta, solía referirse a la «pasta española» obtenida al jaspear la badana blanca con sulfato de hierro. El resto de la colección parece que estaba encuadernada en pergamino. La obra más valorada alcanza los 90 reales, si bien el precio medio se sitúa entre los 10 y un solo real. En cuanto a sus formatos, los ejemplares en $4^{\circ}$ llegan al 52\% de la colección, seguidos de los en $8^{\circ}$ con casi un $40 \%$, mientras que el tamaño faltriquera y el formato en folio apenas cuentan con algún ejemplar (figura 3 ).

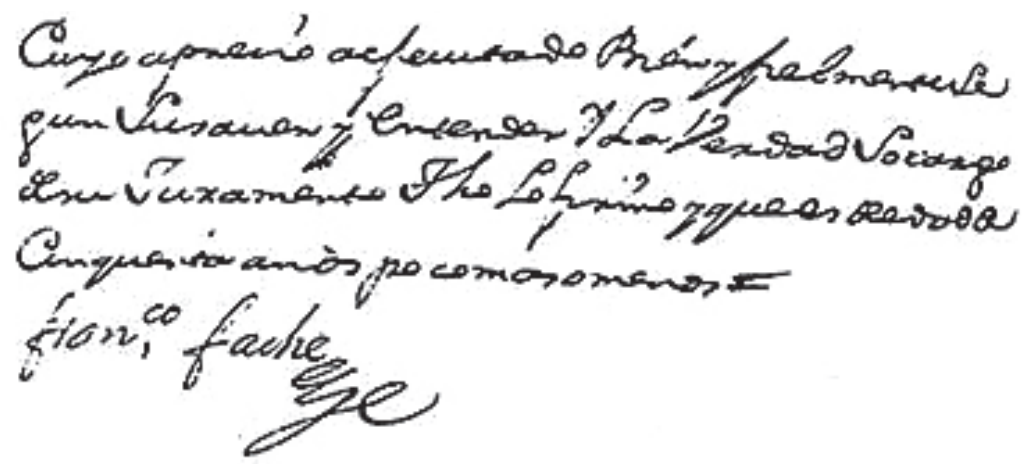

Figura 3. Nota final del expediente de tasación firmado por Fache.

\footnotetext{
32 A.H.P. Murcia. Prot. 2944, 23 r. foliación propia del expediente.

33 Amparo García Cuadrado, «Un francés entre los libreros murcianos del siglo XVIII», Revista General de Información y Documentación 25, n. ${ }^{\circ} 1$ (2015): 141-155. https://doi.org/10.5209/rev_RGID. 2015.v25.n1.48982

${ }^{34}$ A.H.P. Murcia. Prot. 2944, f. 27r.-28v. «Declaración de Francisco Fache».
} 
Pero, sin duda, lo más interesante de esta pequeña colección bibliográfica es conocer su contenido y distribución por materias. ${ }^{35}$ Son tres los campos temáticos en que pueden ser agrupados los títulos que la componen: Religión, Ciencias y Letras. La Religión supone el 27,7\% de los impresos totales, con la presencia de libros de espiritualidad y doctrina, principalmente. La materia Letras es la más exigua, pues tan solo son tres los ejemplares, el 8,3\% de la colección. Por último, un amplio campo que abarca nada menos que el $63,8 \%$ del fondo y que acoge la biblioteca profesional destinada a la formación y ejercicio de la actividad agrimensora. Estaríamos ante un fondo científico integrado por materias básicas o esenciales, pero también por otras complementarias en la formación del lector. ${ }^{36}$ En ella sobresalen con un 58,3\% las disciplinas físico-matemáticas (aritmética, geometría, geografía, etc.), seguidas de los impresos filosóficos (filosofía natural) y los médicos, ambos con el 12,5\%; y un último subgrupo de variado contenido, que hemos denominado «otros», con un 16,6\%.

\section{ANÁLISIS DE LOS IMPRESOS: AUTORES Y TÍTULOS}

Comencemos por exponer en primer lugar lo que consideramos biblioteca profesional, cuyo dueño bien pudo ponerla a disposición de su sobrino Antonio Román Falcón, agrimensor como su tío. Este campo científico se inicia con una obra de carácter enciclopédico, divulgativo y didáctico de 6 tomos en $4^{\circ}$, Ciencia para las personas de corte, espada, y toga, escrita por Monsieur de Chevigni y traducida al castellano por el sacerdote valenciano Juan Bautista Company, quien añadió varias ilustraciones y tratados (Valencia, 1729). Dedicado por el traductor a Fernando VI, serían varias las ediciones, todas valencianas, con buena salida en el mercado hispano, pese a que sus tomos serían expurgados en 1747. ${ }^{37}$ La obra, tasada nada menos que en 75 reales, debió de gozar de

\footnotetext{
${ }_{35}$ En la asignación de materias e identificación de los diversos ítems hemos recurrido al Catálogo Colectivo del Patrimonio Bibliográfico Español y otros catálogos informatizados; para el análisis de su contenido hemos consultado Google Libros.

36 Víctor Infantes, «Las ausencias en los inventarios de libros y de bibliotecas», Bulletin Hispanique 99, n. ${ }^{\circ} 1$ (1997): 281.

${ }_{37}$ Vicente Ximeno, Escritores Del Reyno De Valencia: Chronologicamente Ordenados, vol. 2 (Valencia: Dolz, impresor del Santo Oficio, 1749), 300.
} 
una larga pervivencia, pues conocemos a otros lectores de la aristocracia murciana que la tenían en sus estantes a finales de siglo. ${ }^{38}$

En manos de los Falcón paraba un extenso tratado de Geografía, entendida como una rama de las ciencias físico-matemáticas, donde el autor aborda cuestiones geométricas aplicadas a la esfera, astronomía, climatología, hidrología y mineralogía, junto a curiosidades de historia natural y sagrada escritura. Este «ejemplo mayúsculo de la geografía humanista del siglo XVII» fue estampado en 1681 en las prensas valencianas de Cabrera bajo el título de Nueva Descripcion del Orbe de la Tierra, dedicada a Carlos II por el geógrafo José Vicente del Olmo, secretario del Santo Oficio, y perteneciente al círculo preilustrado o novator valenciano. ${ }^{39}$ Otro nombre inseparable del movimiento de renovación científica es el padre Zaragoza, quien había sido maestro de José Vicente del Olmo y de otros científicos valencianos de finales del siglo XVII. Del afamado jesuita, profesor de matemáticas en el Colegio Imperial de Madrid y asiduo a las tertulias científicas de la capital valenciana durante su estancia en la ciudad, contaba con dos títulos: la Geometria especulatiua y pratica de los planos, y solidos (Valencia, 1671) y la Esphera en comun celeste y terraquea (Madrid, 1675), donde se incluyen un tratado de geometría esférica, otro de astronomía y un tercer libro de cosmología dedicado a compendiar la geografía matemática y física. ${ }^{40}$

Otra geometría del Seiscientos es la "Geometria de Maulleon», probablemente Los Elementos de Euclides, publicado en 1698 por el capitán e ingeniero Larrando de Mauleón, discípulo del matemático y cosmógrafo jesuita Jacobo Kresa. En ella se contienen los libros I a VI de la geometría plana con destino a sus alumnos de la Academia de Matemáticas de Barcelona. ${ }^{41}$ Del maestro catalán Andrés Puig se encuentra su

\footnotetext{
38 Amparo García Cuadrado, «Entre el Barroco y la Ilustración: tres bibliotecas murcianas del Antiguo Régimen», Revista General de Información y Documentación 27, n. ${ }^{\circ} 2$ (2017): 401 https://doi.org/ 10.5209/RGID.58210

39 Alfredo Faus Prieto, «Inquisidor, poeta y geógrafo. José Vicente del Olmo (Valencia, 1611-1696)», Saitabi 62/63 (2012): 93-117.

40 Víctor Navarro Brotons, Disciplinas, saberes y prácticas: Filosofía natural, matemáticas y astronomía en la sociedad española de la época moderna (Valencia: Publicacions de la Universitat de València, 2014), 305-308.

${ }^{41}$ Real Sociedad Matemática Española. http://vps280516.ovh.net/ divulgamat15/ index.php?option $=$ com_content $\&$ view $=$ article $\& i d=10674 \&$ directory $=67 \&$ limitstart $=18 \quad$ (consultado el 15-102019).
} 
Aritmetica especulativa y practiva [sic] y arte del algebra con la explicación de las proposiciones y problemas de Euclides, cuya primera impresión salió en 1672 del taller barcelonés de Lacavallería. El trabajo de Puig muestra un avance sobre la obra del celebrado Pérez de Moya, aunque un retraso evidente frente al avance de las matemáticas europeas. ${ }^{42}$ Pero, en los anaqueles del agrimensor no podía faltar una obra esencial de uno de los preilustrados valencianos de mayor renombre, Juan Bautista Corachán, la Arithmética demonstrada theorico-práctica para lo mathematico y mercantil (Valencia, 1699), varias veces reeditada y traducida al francés; de carácter elemental teórico-práctico, destaca por el empleo sistemático de la notación decimal moderna que sería difundida en España por el autor. ${ }^{43}$ En esta misma línea disponía también de los 9 tomos del Compendio matematico de Tomas Vicente Tosca, otro de los novatores del círculo valenciano (Valencia: Vicente Cabrera, 1715). El Compendio del padre Tosca, ampliamente difundido entre arquitectos y maestros de obras, incluye a diferencia del de Corachán «un capítulo de aplicación del álgebra a la geometría» y explica de manera didáctica la utilidad de las matemáticas en el desarrollo de la filosofía natural, entre otras cuestiones. ${ }^{44}$ Se trata del ejemplar más caro de la colección ya que fue tasado en 90 reales.

La Antorcha aritmethica practica, provechosa para tratantes, y mercaderes de Juan Antonio Taboada y Ulloa (Madrid, 1731) es otro título que venía a alumbrar, aunque con menor intensidad que los autores ya citados, «las Reglas principales y más usuales de la Aritméthica» con objeto de instruir a «los más jóvenes, mancebos de mercaderes y demás comerciantes para que entiendan el modo de ejecutar sus operaciones», según declaraba el censor civil designado por el Consejo de Castilla en su dictamen. Otro manual de contabilidad en poder de Falcón era El contador moderno del zaragozano Valerio Verbedel, Contador mayor del conde de Aguilar, estampado en Madrid en 1734.

\footnotetext{
${ }^{42}$ Rafael Rodríguez Vidal, «Notas para una nómina de matemáticos españoles del siglo XVII», en El científico español ante su historia. La ciencia en España entre 1750-1850, coord. Santiago Garma Pons, (Madrid: Diputación Provincial, 1980), 369.

43 Antonio Martínez Naveira, Sobre la historia de las matemáticas en Valencia y en los países mediterráneos (Valencia: Universitat de València, 1998), 63.

${ }^{44}$ Martínez Naveira, Sobre la historia, 65.
} 
Directamente relacionado con una faceta de su quehacer profesional contaba con la Primera y precisa geometria o reglas y estadal de medir tierras para gobierno de los agrimensores y labradores de Sánchez de Villajos, alarife y maestro de obras madrileño. Conocemos la segunda edición de la obrita estampada en Madrid por Zúñiga en 1752; su interés radica en extender sus datos sobre medidas a las variantes utilizadas en otras ciudades ante la diversidad de sistemas existentes. ${ }^{45} \mathrm{La}$ elaboración del manual, según su autor, obedecía al carácter excesivamente teórico de los textos anteriores, aunque por supuesto no desdeñaba a Pérez de Moya, el padre Zaragoza, Tosca o Corachán, cuyos manuales podían ser de difícil compresión para los agrimensores. ${ }^{46}$ Pese a contar con este moderno trabajo disponía también de un antiguo tratado en la materia: el Libro de instrumentos nueuos de Geometría muy necessarios para medir distancias y alturas sin que interuengan numeros, compuesto por el ingeniero, astrónomo y socio de la Academia de Matemáticas matritense don Andrés García de Céspedes (Madrid, Juan de la Cuesta, 1606). En sus páginas se incluye un tratado de hidráulica, el más amplio publicado en España en su tiempo. ${ }^{47}$

Otro impreso utilizado para afrontar con acierto sus trabajos profesionales fue, sin duda, el titulado Dificultades vencidas y curso natural en que se dan reglas especulativas y practicas para la limpieza y asseo de las calles de esta corte, un impreso en $4^{\circ}$, cuyo autor, el ingeniero y agrimensor José Alonso de Arce, daría a las prensas en Madrid en 1735. Alonso de Arce, que había sido aprobado como agrimensor en las aulas de la Compañía de Jesús de la Corte, desempeñaba como profesor de arquitectura y maestro de obra del Real Consejo. En tal condición, le fue encomendada la limpieza de las calles madrileñas de aguas estancadas, malos olores e inmundicias, causa de no pocas enfermedades entre los vecinos. El proyecto diseñado por el geómetra madrileño tenía su fundamento en las ideas propuestas con anterioridad por el arquitecto Teodoro Ardemans en su tratado Fluencias de la tierra y curso subterráneo de las aguas (Madrid, 1724). Su práctico contenido bien pudo servir a Falcón

\footnotetext{
45 Francisco José León Tello y $\mathbf{M}^{\mathrm{a}}$ Virginia Sanz Sanz, Estética y teoría de la arquitectura en los tratados españoles del siglo XVIII (Madrid: CS.I.C., 1994), 445.

46 Faus Prieto, «El ejercicio profesional», 433.

47 Navarro Brotons, Disciplinas, saberes, 55.
} 
en la correcta realización de las obras de saneamiento de las algunas calles murcianas en 1738, un dato que muestra la actualidad de la bibliografía consultada para afrontar los trabajos de ingeniería urbana que le fueron encomendados. ${ }^{48}$ Es el mismo papel que debió de cumplir la lectura de las Ordenanzas de Madrid, y otras diferentes que se practican en las ciudades de Toledo, y Sevilla, texto preparado por el ya citado Ardemans a partir de las ordenanzas del alarife de la villa madrileña Juan de Torija (1661). El tratado del arquitecto y pintor publicado en 1719 fue objeto de numerosas ediciones y de gran influencia entre arquitectos y maestros de obras quienes lo incorporaron a sus bibliotecas por encontrar en él «un lúcido compendio» de normas fijadas para ordenar modernamente el espacio urbano. ${ }^{49}$

En materia filosófica, Falcón había adquirido para su biblioteca dos tomos en $4^{\circ}$ de una "Filosofía en práctica», que no hemos identificado, junto a dos impresos de filosofía natural o cosmología de signo muy diferente, a saber: El filosofo [...] sobre los libros de cielo y mundo, meteoros, paruos naturales, ethica, economica, politica de Aristoteles y esfera de Sacro Bosco [...] en dos libros, Filosofo natural, y Filosofo moral del humanista escolástico Cosme Gómez Tejada de los Reyes (Madrid, 1650), y uno de los tomos de la Filosofia racional, natural, metafisica i moral (Valencia, 1736) del antiescolástico y novator valenciano Juan Bautista Berni, discípulo de Tosca y defensor de la especulación racional y de la experimentación en física.

La materia médica estaba presente en aquellos anaqueles con un solo tomo de El antiguo academico, contra el moderno sceptico, rigido, ò moderado: defensa de las ciencias y especialmente de la Physica Pytagorica, y Medica de Luis de Flandes (Madrid, 1743), impreso que aborda las controversias médicas de la época; el capuchino atacará las posturas defendidas por el maestro Feijoo, quien había polemizado con Flandes en sus

\footnotetext{
48 Según el acta concejil del día 11 de noviembre de 1738, se ordenó pagar a Francisco Falcón 8 reales por cada día empleado en el empedrado de la Placeta de San Pedro hasta la boquera del Porche de Verónicas, trabajos a los que había asistido personalmente, igual que a las nivelaciones para dar salida a las aguas de la boquera de la Plaza Nueva, dirigiéndolas por el Porche de Nuestra Señora del Pilar, f. 300r.

${ }^{49}$ Real Academia de la Historia, Diccionario Biográfico electrónico, http://dbe.rah.es/biografias/ 7689/ teodoro-ardemans. (consultado el 16-11-2019), y Alfonso Rodríguez G. de Ceballos, «Las Ordenanzas de Madrid, de don Teodoro Ardemans, y sus ideas sobre la Arquitectura», Revista de ideas estéticas 114 (1971): 3-22
} 
Cartas eruditas (carta IV). Dentro del mismo contexto de desprestigio de la Medicina se encuentra otro título muy conocido en España, El mundo engañado de los falsos médicos del doctor José Gazola, traducido del toscano por el ilustrado Mayans y Siscar, quien ocultó su nombre (Valencia, 1729). El autor se propuso realizar «una apología de la verdadera arte médica y una justa invectiva contra aquellos que hacen inhumano destrozo de vidas humanas por hacerse de oro, aunque sea a costa de sus muchos yerros». ${ }^{50} \mathrm{El}$ éxito de la obra era señalado por el prologuista de la $4^{a}$ impresión que salía al mercado en el espacio de tres años (Valencia 1733), no en balde, el propio Feijoo lo calificaba de excelente en el discurso sobre «El Médico de sí mismo» recogido en su Theatro critico universal. ${ }^{51}$ El último título de la especialidad, de mayor interés para las féminas de la familia, eran las Questiones generales sobre el modo de partear y cuydar a las mugeres que estan embarazadas o parideras (Madrid, 1717), un nuevo tratado sobre la materia escrito por el cirujano francés Pablo Petit, quien había ejercido en Madrid y más tarde en Cataluña como Cirujano mayor de Artillería antes de su establecimiento en la ciudad de Lima.

Dentro de esta biblioteca de ciencias se encontraban también «otros» títulos de interés para este experto matemático y comerciante ocasional. Entre ellos se encuentra un texto de economía política, Restablecimiento de las fabricas y Comercio español (Madrid, 1740) de Bernardo de Ulloa, discípulo de Ustáriz y representante del primer reformismo borbónico, quien trataba de averiguar las causas de la decadencia económica española y los remedios para su activación. Junto a este tratado mercantilista dedicado a Felipe V, disponía Falcón de dos impresos de jurisprudencia que tal vez ayudaran a su dueño en sus desencuentros con la Administración, pero también en su trabajo profesional como perito en los tribunales. Nos referimos a la Practica de procuradores para seguir pleytos civiles, y criminales de Juan Muñoz, un clásico manual del siglo XVI que seguirá editándose en las prensas madrileñas y barcelonesas en los siglos siguientes, y al ítem "Escrito de Melgarejo», tal vez el Compendio de contratos publicos, autos de particiones y executiuos, recopilados

\footnotetext{
${ }^{50}$ Miguel López Pérez, «Los hijos de Paracelso», Studia Hermetica Journal 6, n. ${ }^{\circ} 2$ (2016): 90-91 file:///C:/Users/Administrador/Downloads/Dialnet-LosHijosDeParacelso-5767151.pdf

${ }^{51}$ Benito Feijoo y Montenegro, Theatro critico universal, vol. IV (Madrid: Pedro del Hierro, 1730), 70.
} 
en el siglo XVII por Pedro Melgarejo Manrique de Lara, que conocería numerosas ediciones durante el XVIII. Por último, vemos anotado Errores de Mañer en la coleccion y notas de la Bula de Oro y crysis de ella: en un discurso apologético (Madrid, 1743) del abogado de los Reales Consejos y corregidor de Madrigal Francisco Curcio Palomino sobre el derecho sucesorio alemán y los errores cometidos por Salvador José Mañer en su estudio sobre el tema publicado en 1741 .

Pasemos ahora a analizar la materia Religión, otro campo bastante bien representado en atención al número de títulos anotados en el inventario de los libros de esta peculiar familia de «cristianos nuevos». Además de contar con un texto litúrgico, la «Práctica de la Misa», probablemente la escrita por el obispo oriolano Juan Elías Gómez de Terán, que conocería varias ediciones en diferentes formatos, la colección de impresos religiosos destacaba por la presencia de libros de doctrina. Así, encontramos desde el famoso Caton christiano de Gerónimo Rosales, cuyo privilegio de impresión y venta en tierras murcianas anduvo en manos de varios libreros de la ciudad ${ }^{52}$, al Catecismo en practica con la Theología del ya citado fraile capuchino Luis de Flandes (Orihuela, 1727), ${ }^{53}$ más dos ejemplares de la Filosofia del verdadero christiano, intitulada, Piensalo bien, impreso catequético del siglo XVII, para concluir con el Tesoro catolico y moral: en que hallaran los fieles muy explicado todo lo que han de procurar saber y entender, cuya segunda impresión madrileña salía de las prensas de viuda de Melchor Álvarez en 1704. Pero, además, en aquella colección no estaba ausente el más conocido texto de espiritualidad mariana, la Mystica ciudad de Dios de la madre Ágreda, 10 tomos encuadernados en pasta francesa, obra con fuerte presencia en las bibliotecas de la época, igual que ocurría con la Imitación de Christo de Kempis, traducida por el jesuita Nieremberg y presente también entre aquellos ejemplares. Finalmente vemos anotado un libro en pasta del místico Palafox, cuyo título no se concreta, y una gruesa y antigua hagiografía, El Fenis de Africa, vida de nuestro P. San Augustin (Zaragoza, 1674), dedicada por su autor a don Juan de Austria.

\footnotetext{
52 Amparo García Cuadrado, «Cesión del privilegio de impresión de libros doctrinales para el Reino de Murcia», Tejuelo, Revista de ANABAD-Murcia 9 (2009): 36-45.

53 Juan Torres Fontes, «Notas sobre dos cartas de Feijoo», en Amica Verba in honorem prof. Antonio Roldán Pérez, coord. Ricardo Escavy Zamora, vol. II (Murcia: Universidad de Murcia; Servicio de Publicaciones, 2005), 998.
} 
Descendiendo en la escala de intereses lectores se anotan unos pocos impresos literarios como son los dos tomos en pergamino de El entretenido: segunda parte, una miscelánea de variados asuntos en prosa y verso "seri-jocoso, y burlesco», compuesto por un escribano de S.M., José Moraleja, a imitación del escrito por Sánchez Tórtoles en 1671. A este entretener provechoso le siguen unos «conceptos poéticos» en $4^{\circ}$ y en el mismo formato otro impreso de "poesía» sin mayor aclaración. Hasta aquí el elenco de títulos y autores en poder de los Falcón una vez mediada la centuria.

\section{¿QUÉ PODEMOS CONCLUIR?}

Con los datos analizados y expuestos en estas páginas son varias las cuestiones que llaman nuestra atención. En primer lugar, la importancia cuantitativa y cualitativa de lo que consideramos biblioteca profesional de este técnico municipal de la primera mitad del siglo XVIII en la ciudad de Murcia. En los anaqueles del agrimensor estaban presentes aquellas materias sin cuyo conocimiento nunca hubiera podido ejercer con éxito las tareas que le fueron encomendadas. En este punto, podemos señalar que la elección de autores y títulos de la biblioteca obedecía a una motivación concreta: su formación profesional.

A través de este fondo de carácter científico podemos conocer a uno de aquellos receptores del proceso renovador de la ciencia española iniciado a finales del siglo XVII y principios del XVIII. Las obras del padre Zaragoza y los novatores valencianos (del Olmo, Corachán, Tosca, Berni), junto con las de algún integrante del círculo catalán (Larrando de Mauleón y Andrés Puig), nos dibujan un geómetra con una más que notable preparación científica, que nada tenía que ver con las carencias formativas de este colectivo durante la primera mitad de la centuria en Murcia y en la propia Valencia, foco de irradiación de la ciencia preilustrada. No sería extraño que la actividad profesional desarrollada en el Reino valenciano favoreciese los contactos con los novatores y, en consecuencia, el conocimiento de los autores y textos más representativos de las corrientes científicas periféricas.

Por otra parte, su cercanía al mundo de la librería pudo haberle facilitado la adquisición de títulos directamente relacionados con los trabajos que debía de abordar puntualmente. Y no nos referimos a los manuales 
destinados a los propios agrimensores adaptando y aplicando las matemáticas a la medición del agro (Sánchez de Villajos), sino a aquellos otros que podríamos denominar de ingeniería urbana (José Alonso de Arce, Ardemans) para afrontar, como técnico especialista, obras de salubridad en plazas y calles de la capital del Segura.

Llama también la atención la presencia de impresos de contabilidad, materia en la que debió alcanzar una adecuada preparación para desenvolverse entre comerciantes y mercaderes, del mismo modo que hubo de informarse acerca de algunas cuestiones judiciales para afrontar con acierto la defensa de sus intereses ante los tribunales; estos mismos conocimientos debieron serle de utilidad en el propio quehacer profesional como perito nombrado en litigios sobre tierras, una faceta importante del trabajo del agrimensor.

Por último, no puede sorprendernos el contenido de los fondos religiosos recogidos en el inventario y que destacan, fundamentalmente, por su valor catequético en una familia de cristianos nuevos. Los títulos anotados nos hablan del interés por lograr una formación religiosa en sus diversos niveles, desde el básico Catón a la Filosofia del verdadero christiano con destino a la juventud, hasta un completo Tesoro catolico y moral para todos los fieles. Y tras una adecuada formación en las verdades de la fe, nada mejor que la lectura de los clásicos espirituales: Kempis, Madre Agreda, Palafox..., buenas meditaciones que no impedirían alguna que otra lectura hagiográfica, poética o narración divertida, en definitiva, un entretener provechoso como exigían los tiempos.

\section{Nota sobre la autora}

Amparo García Cuadrado es profesora de Biblioteconomía y Documentación de la Universidad de Murcia desde 1989, y forma parte del grupo de investigación Bibliotecas, Archivos y Cultura de la Información. Su interés investigador se ha centrado en la Historia del Libro desde su tesis doctoral dedicada a analizar el valor documental de la imagen miniada en el códice F de Las Cantigas de Santa María (Las Cantigas: el Códice de Florencia, 2003). El acercamiento a la materialidad del libro manuscrito se amplió más tarde al libro impreso y su proceso de edición, a la Historia de la Imprenta y de la Librería. Tiene publicados una treintena de 
trabajos sobre estas cuestiones, principalmente centrados en el siglo XVIII. Una constante de sus publicaciones ha sido poner de relieve el valor de las fuentes documentales para historiar el complejo mundo del libro impreso y de su comercio durante la Edad Moderna. Resultado de este esfuerzo investigador son La librería en el siglo XVIII: el murciano Juan Polo Ruiz (2010) y Los Benedicto, una familia de mercaderes de libros en Murcia (siglos XVIII-XIX) (2014). En la actualidad se encuentra trabajando en la Historia de la Lectura, campo que puede dar excelentes frutos mediante el análisis de las bibliotecas privadas. Esta línea de investigación sobre la lectura se inicia en 2013 con "Lecturas y lectores en la Murcia decimonónica”. Más recientes son los trabajos dedicados a analizar los libros en poder de la elite murciana, su transmisión de padres a hijos y la incorporación de nuevos títulos según la formación, los gustos o las necesidades de los nuevos lectores.

\section{REFERENCIAS}

Arias de Saavedra, Inmaculada. «Libros, lectores y bibliotecas privadas en la España del siglo XVIII». Chronica nova 35 (2009): 15-61.

Azanza López, José. «La biblioteca de Juan de Larrea, maestro de obras del siglo XVIII». Príncipe de Viana 211 (1997): 295-328.

Faus Prieto, Alfredo. Mapistes. Cartografía i agrimensura a la València del segle XVIII. Valencia: Edicions Alfons el Magnànim; Generalitat Valenciana, 1995.

Faus Prieto, Alfredo. «El ejercicio profesional de la agrimensura en la España del siglo XVIII: titilación académica y formación teórica de los peritos agrimensores». Llull 18 (1995): 425-440.

Faus Prieto, Alfredo. «Inquisidor, poeta y geógrafo. José Vicente del Olmo (Valencia, 1611-1696)». Saitabi 62/63 (2012): 93-117.

García Cuadrado, Amparo. «Cesión del privilegio de impresión de libros doctrinales para el Reino de Murcia». Tejuelo, Revista de ANABAD-Murcia 9 (2009): 36-45.

García Cuadrado, Amparo. «Noticias sobre el impresor Felipe Teruel Martínez». Anales de Documentación 18 (2015). https://digitum.um.es/digitum/ bitstream/10201/44071/1/ document\%20\%2848\%29.pdf

García Cuadrado, Amparo. «Un francés entre los libreros murcianos del siglo XVIII. Revista General de Información y Documentación 25, no. 1 (2015): 141-155. https://doi.org/10.5209/rev_RGID.2015.v25.n1.48982

García Cuadrado, Amparo. «Entre el Barroco y la Ilustración: tres bibliotecas murcianas del Antiguo Régimen». Revista General de Información y Documentación 27, no. 2 (2017): 383-407. https://doi.org/10.5209/RGID.58210 
Gil Saura, Yolanda. «Pedro Juan Laviesca de la Torre, un arquitecto itinerante en la España del siglo XVIII». Anuario del Departamento de Histona y Teoria del Arte 11 (1999): 169-183.

Giol y Soldevilla, Isidro. Tratado de Agrimensura. $3^{\circ}$ ed. corr. y aum. Madrid, 1889.

Infantes, Víctor. «Las ausencias en los inventarios de libros y de bibliotecas». Bulletin Hispanique 99, no. 1 (1997): 292283.

León Tello, Francisco José y Sanz Sanz, Ma Virginia. Estética y teoría de la arquitectura en los tratados españoles del siglo XVIII. Madrid: CS.I.C., 1994.

López Pérez, Miguel. «Los hijos de Paracelso». Studia Hermetica Journal 6, no. 2 (2016): 69-104. Disponible en: file://C:/Users/Administrador/Downloads/ Dialnet-LosHijosDeParacelso-5767151.pdf

Marín Cruz, $\mathrm{M}^{\mathrm{a}}$ Dolores. «La Libertad y su Criada, la Esclavitud». Cuadernos de Historia del Derecho, vol. extr. (2010): 277-302.

Martínez Naveira, Antonio. Sobre la historia de las matemáticas en Valencia y en los países mediterráneos. Valencia: Universitat de València, 1998.

Navarro Brotons, Víctor. Disciplinas, saberes y prácticas: Filosofía natural, matemáticas y astronomía en la sociedad española de la época moderna. Valencia: Publicacions de la Universitat de València, 2014.

Peña Velasco, Concepción, de la. «La biblioteca de Martín Solera, un maestro de obras del siglo XVIII en Murcia». Imafronte 1 (1985): 73-86.

Peña Velasco, Concepción de la. El Puente Viejo de Murcia. Murcia: Universidad de Murcia, 2001.

Ramiro, Francisco José. «Alfabetización, lecturas y bibliotecas en la Granada del siglo XVIII». PhD diss., Universidad de Granada, 2017. Tesis en acceso abierto, https://dialnet.unirioja.es/servlet/tesis?codigo=147594

Rodríguez Vidal, Rafael. «Notas para una nómina de matemáticos españoles del siglo XVII». En El científico español ante su historia. La ciencia en España entre 1750-1850, coordinado por Santiago Garma Pons, 365-370. Madrid: Diputación Provincial, 1980.

Rodríguez G. de Ceballos, Alfonso. «Las Ordenanzas de Madrid, de don Teodoro Ardemans, y sus ideas sobre la Arquitectura». Revista de ideas estéticas 114 (1971): 3-22.

Taín Guzmán, Miguel. «El taller y la biblioteca del maestro de obras compostelano José de Seixas». Cuadernos de Estudios Gallegos 106 (1993/94): 263275.

Torres Fontes, Juan. «Notas sobre dos cartas de Feijoo». En Amica Verba in honorem prof. Antonio Roldán Pérez, coordinado por Ricardo Escavy Zamora, vol. II, 995-1000. Murcia: Universidad de Murcia; Servicio de Publicaciones, 2005. 
Viñao Frago, Antonio. «La historia de la alfabetización a través de las fuentes notariales. Aportaciones provisionales sobre el proceso de alfabetización en Murcia (1760-1860)». En Aproximación a la investigación histórica a través de la documentación notarial, compilado por Antonio Eiras Roel y otros, 31-35. Murcia: Universidad, 1985.

Ximeno, Vicente. Escritores Del Reyno De Valencia: Chronologicamente Ordenados, vol. 2. Valencia: Dolz, impresor del Santo Oficio, 1749. 